\title{
FLASH BUTT WELDING OF RAILWAY FROGS THROUGH CAST AUSTENITIC INSERT
}

\author{
S.I. KUCHUK-YATSENKO ${ }^{1}$, Yu.V. SHVETS ${ }^{1}$, A.V. KAVUNICHENKO ${ }^{1}$, V.I. SHVETS ${ }^{1}$, \\ S.D. TARANENKO ${ }^{1}$ and V.A. PROSHCHENKO ${ }^{2}$ \\ ${ }^{1}$ E.O. Paton Electric Welding Institute, NASU \\ 11 Bozhenko Str., 03680, Kiev, Ukraine. E-mail: office@paton.kiev.ua \\ ${ }^{2}$ Company «Dnepropetrovsky Strelochny Zavod» \\ 181 Belostotsky Str., 49098, Dnepropetrovsk, Ukraine
}

\begin{abstract}
The technology of flash butt welding of rail frogs with rail ends using an austenitic insert of rolled metal of stainless steel of type 18-10 has found a wide application. In the present paper the experiments on evaluation of possibility of using a shaped casting of steel of type 18-10 as an insert are described. It is shown that fundamental differences in the structure and properties of metal of different zones of welded joints using rolled or cast inserts are not observed. Further increase in efficiency and physical and mechanical properties of welded joints can be realized by optimizing the chemical composition and structure of the insert metal. 8 Ref., 3 Tables, 2 Figures.
\end{abstract}

Key words: flash butt welding, pulsed flashing, high-manganese steel 110G13L, rail steel M76, austenitic insert, welded joints, chemical composition, $\delta$-ferrite, mechanical properties

In 1990 the company «Vereinigte Oesterreichische Eisen und Stahlwerke-Alpine Montan AG» (Austria) proposed a method of joining parts of switches of austenitic high-manganese steel casting with the rail of carbon steel [1], at which the austenitic insert of chrome-nickel steel of type $18-10$, stabilized by niobium or titanium, is used. Moreover the content of niobium in the insert must be at least 10 -fold, and that of titanium not less than 5-fold of carbon content.

In 1990 at the E.O. Paton Electric Welding Institute the technology of joining of rail frogs of high-manganese steel $110 \mathrm{G} 13 \mathrm{~L}$ with rail ends of steel M76 was developed using the method of flash butt welding with a pulsating flashing [2]. The distinctive feature of this technology is the ability to produce quality joints at the minimum energy input, providing minimization or elimination of formation of the undesired structural transformations in welds capable to reduce the ductile properties of the joints. This opened up the new possibilities for optimizing the welding technology, in particular, allowed reducing the requirements to regulation of chemical composition of the insert and eliminating power-intensive heat treatment operation.

This technology was successfully implemented at the company «Dnepropetrovsky Strelochny Zavod». During 14 years about 1,500 rail frogs with welded-in ends were welded and suc- cessfully operated. A considerable experimental material [3-7] was accumulated, which allowed improving the welding technology, specifying the requirements to the composition of steel 110G13L, in particular, as to the content of phosphorus in it, evaluating the structural and phase states in different zones of welded joint and the metal of insert. It was also established that preparation of austenitic semi-products of standard rolled sheet metal of steels of type 18-10 is associated with increase in labor intensity of works and, in a number of cases, their chemical composition did not satisfy the quality requirements of the produced joints. Thus, in some specimens of welded frogs in the area of metal of type 18-10 steel insert (free from $\delta$-ferrite) close to the fusion boundary with the rail steel, intergranular microcracks were detected having the character of hot microcracks.

Furthermore, during the test of joints for static bending the most frequent locations of fracture appeared to be the areas of base metal near the fusion line on the side of rail steel M76 [3]. The cracks bear longitudinal nature oriented along the axis of joint zone, and are probably associated with delayed fracture, initiated by martensitic transformation.

The aim of this work was to establish at the first stage the possibility of using cast austenitic inserts of stainless steel of type 18-10 in the joint of frogs with rail ends. In case of a positive result it is possible further to optimize the chemical and structural composition of the insert to provide high levels of mechanical properties of the joints. 


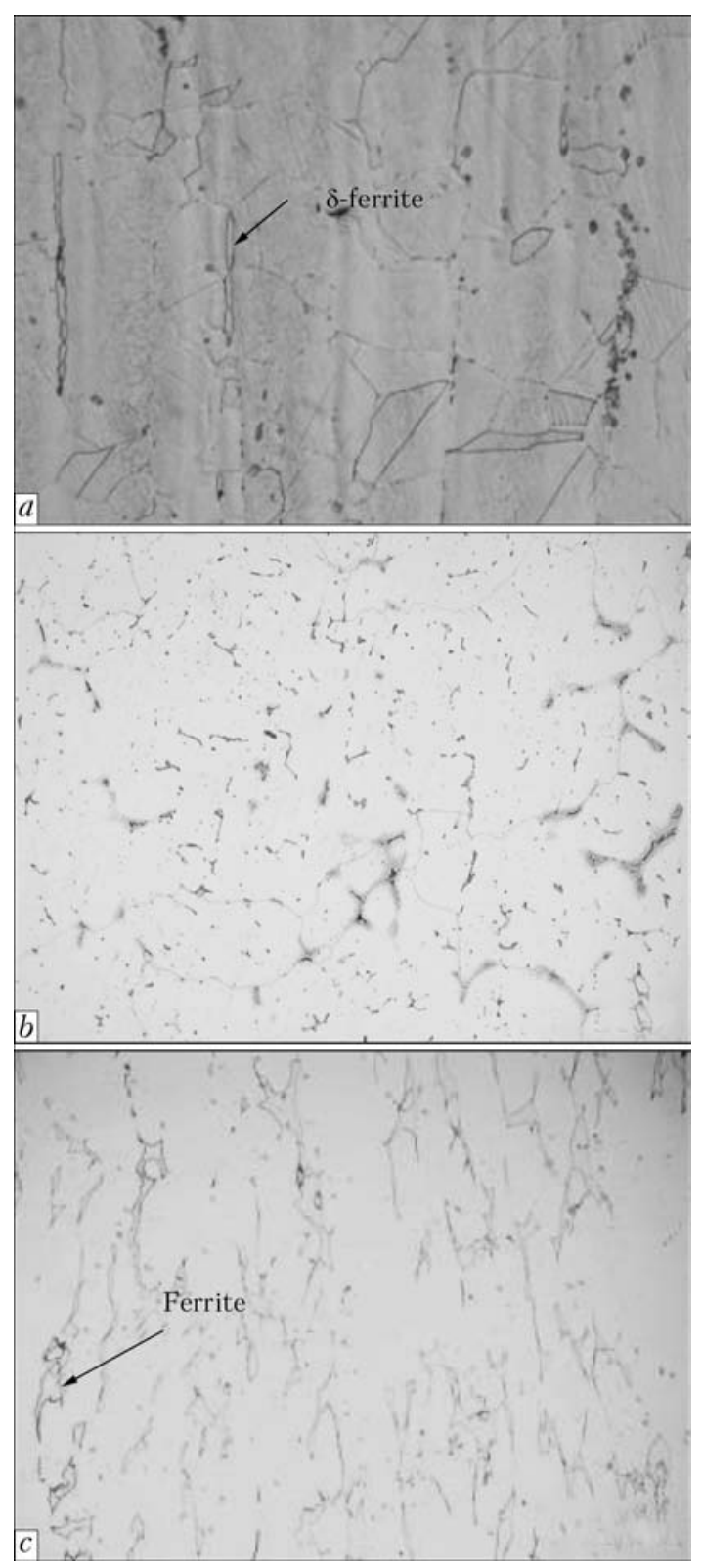

Figure 1. Microstructure of chrome-nickel insert: $a$ - rolled steel; $b$ - cast steel $1 ; c-$ cast steel $2(a-\times 250 ; b, c-$ $\times 100$ )

The works were carried out jointly with the specialists of «Dnepropetrovsky Strelochny Zavod» using the equipment for production of shaped casting of austenitic steel available at the Plant.

The chemical composition of the insert was controlled by spectral analysis. The welding of specimens was performed at basic mode [3]. Me-
Table 1. Chemical composition of inserts

\begin{tabular}{||c|c|c|c|c|c|c||}
\hline \hline \multirow{2}{*}{$\begin{array}{c}\text { Type of } \\
\text { insert }\end{array}$} & \multicolumn{6}{|c|}{ Mass fraction of elements, \% } \\
\cline { 2 - 7 } & $\mathrm{C}$ & $\mathrm{Cr}$ & $\mathrm{Ni}$ & $\mathrm{Ti}$ & $\mathrm{S}$ & $\mathrm{P}$ \\
\hline Rolled & 0.08 & 17.8 & 9.7 & 0.57 & 0.006 & 0.03 \\
\hline Cast 1 & 0.05 & 21.3 & 11.5 & 0.07 & 0.005 & 0.02 \\
\hline Cast 2 & 0.17 & 19.0 & 9.9 & 0.09 & 0.006 & 0.03 \\
\hline
\end{tabular}

tallographic examinations were carried out in optical microscope «Neophot-32» and in scanning electron microscope JAMP $9500 \mathrm{~F}$. After welding of specimens and grinding of joint surface it was subjected to non-destructive (capillary) testing. The mechanical tests on static bending were carried out in hydraulic press MPS-300 according to the requirements of [8].

In Table 1 the chemical composition of rolled and pilot cast inserts is shown. Figure 1 shows microstructure of metal of the inserts.

The microstructure of rolled insert optimal by its chemical composition represents a typical structure of polygonal austenite with inclusions of $\delta$-ferrite elongated along the direction of rolling (Figure 1, $a$ ). The microstructure of cast insert 1 (Figure $1, b$ ) is typical of the cast state. Its base is composed of primary austenite grains. Between austenite grains the ferrite grains are located, edged with more etched areas, probably caused by intergranular liquation. In microstructure of cast alloy 2 the volume fraction of ferrite is higher. The inclusions of ferrite are edged with a structural component of dark color, enriched with titanium.

In the macrostructure of welded joint ( $\mathrm{Fi}^{-}$ gure 2) such typical areas are observed:

- transition zone at the interface of rail steel M76 and insert; and

- transition zone at the interface of steel $110 \mathrm{G} 13 \mathrm{~L}$ and insert.

The structural components in the transition zones of welds with cast insert are similar to those formed using the rolled insert [3-5].

The transition zone at the interface of steel 110G13L and cast insert has a stable austenitic structure. Its distinctive feature is the presence of increased content of chromium and nickel in the near-contact layer of steel 110G13L.

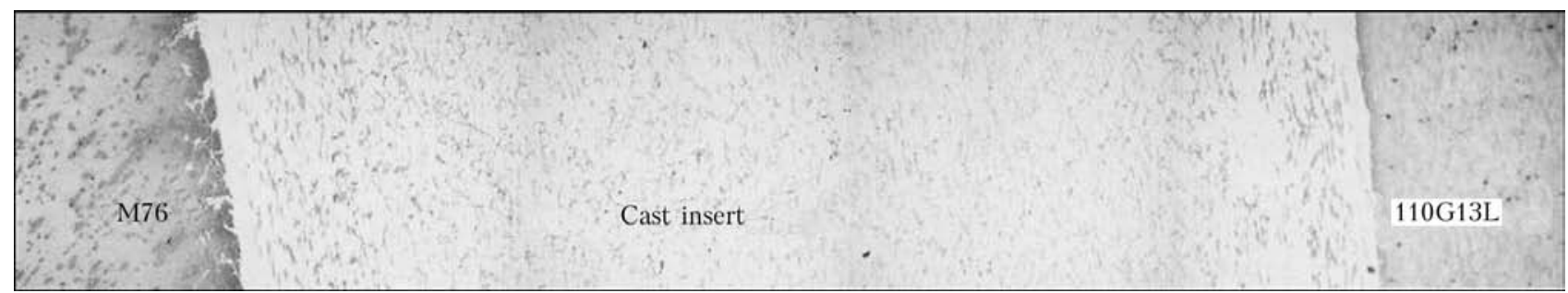

Figure 2. Macrostructure $(\times 25)$ of welded joint of frog with rail ends 
Table 2. Mechanical properties of parent metal of insert

\begin{tabular}{||c|c|c|c|}
\hline $\begin{array}{c}\text { Type of } \\
\text { insert }\end{array}$ & $\begin{array}{c}\text { Tensile strength, } \\
\mathrm{MPa}\end{array}$ & $\begin{array}{c}\text { Yield strength, } \\
\mathrm{MPa}\end{array}$ & $\begin{array}{c}\text { Elongation, } \\
\%\end{array}$ \\
\hline Rolled & $480-520$ & $200-220$ & $40-44$ \\
\hline Cast 1 & $387-474$ & $205-263$ & $36-58$ \\
\hline
\end{tabular}

Near the boundary of joint of steel M76 with the cast insert (on the side of steel M76), as well as in the joint with the rolled inserts, local formation of hardening structures is possible that can reduce the ductile properties of joints in this area.

Table 2 shows the results of testing the mechanical properties of parent metal of inserts. The test results show that the insert metal meets the requirements to inserts as to yield strength (200-250 MPa) and elongation (40\%).

The test results of specimens on static bending are shown in Table 3.

One of the reasons of more stable mechanical properties of welded joints produced through the cast insert may consist in the fact that non-metallic inclusions in them have a globular shape and are relatively uniformly distributed across the section of insert, and in the rolled insert they are concentrated in strips of rolling and so during welding the probability of getting them to the butt zone is higher.

Thus, the prospects of application of cast inserts in the joints of railway frogs with rail ends in flash butt welding using pulsating flashing are experimentally confirmed. The further investigations on optimization of chemical and structural composition of the insert metal are rational in
Table 3. Test results of welded specimens on static bending (profile R65)

\begin{tabular}{||l|c|c|}
\hline \hline Type of insert & Fracture force, $\mathrm{N}$ & Bending deflection, mm \\
\hline Rolled & $\frac{940-1330}{1115}$ & $\frac{16-36}{22.5}$ \\
\hline Cast 1 & $\frac{1120-1190}{1140}$ & $\frac{29-48}{38}$ \\
\hline Cast 2 & $\frac{855-1100}{994}$ & $\frac{18-29}{24}$ \\
\hline
\end{tabular}

order to improve the efficiency of process and stability of mechanical properties.

1. (1991) European application for patent $0467881 A 1$. Publ. Number 91890157.0.

2. Kuchuk-Yatsenko, S.I., Didkovsky, O.V., Bogorsky, M.V. et al. Method of resistance butt welding. Pat. 46820 Ukraine. Publ. 17.06.02.

3. Kuchuk-Yatsenko, S.I., Shvets, Yu.V., Dumchev, E.A. et al. (2005) Flash-butt welding of railway frogs with rail ends using an intermediate insert. The Paton Welding J., 1, 2-4.

4. Kuchuk-Yatsenko, S.I., Shvets, Yu.V., Gordan, G.N. et al. (2006) Features of formation of structure of joints of rail steel M76 to steel 110G13L made by flash-butt welding. Ibid., 1, 2-8.

5. Kuchuk-Yatsenko, S.I., Shvets, Yu.V., Kavunichenko, A.V. et al. (2007) Influence of the width of stainless steel insert on performance of joints of railway frogs with rail ends. Ibid., 3, 2-5.

6. Kuchuk-Yatsenko, S.I., Shvets, Yu.V., Kavunichenko, A.V. et al. (2008) Performance of flash butt welded joints on railway frogs. Ibid., 9, 30-33.

7. Kuchuk-Yatsenko, S.I. Shvets, V.L. Shvets, Yu.V. et al. (2010) Causes of crack formation in the HAZ of cast high-manganese steel in flash-butt welding. Ibid., 7, 4-7.

8. TUU 27.3-26524137-1342:2006: Frogs and points with welded-on rail ends of R65, R50 and UIC60 type. Valid from 10.08.2006.

Received 05.06.2015 